\title{
Carbon and mercury stable isotope fractionation during aqueous $\mathrm{MeHg}$ photoreduction
}

LUISA M MALBERTI ${ }^{1}$, CHRISTELLE LAGANE ${ }^{1}$, JEROEN E SONKE $^{2}$ AND DAVID POINT ${ }^{1}$

${ }^{1}$ Géosciences Environnement Toulouse, CNRS/IRD/Université Paul Sabatier Toulouse III

${ }^{2} \mathrm{CNRS} /$ Université de Toulouse

Presenting Author: 1malberti1996@gmail.com

The natural processes of breakdown and formation of chemical species often act as isotopic filters that leave characteristic traces (fingerprints) in the isotopic composition of compounds. These fingerprints can be used then to investigate the biogeochemical pathways and/or to trace the origin of certain pollutant compounds of interest like mercury ( $\mathrm{Hg}$ ). In 2007 Bergquist and Blum[1] studied the $\mathrm{Hg}$ stable isotopic fractionation during the photochemical reduction and decomposition of mercury compounds $\left(\mathrm{Hg}^{2+}\right.$ and methyl mercury (MeHg), respectively) in water samples. Later, in 2010, Zhang and Hsu-Kim[2] investigated more specifically the role of dissolved organic ligands on $\mathrm{Hg}$ stable isotopic fractionation during the photodegradation of $\mathrm{MeHg}$. However, what happens to the stable isotopic composition of the carbon atom of the methyl $\left(-\mathrm{CH}_{3}\right)$ group during $\mathrm{MeHg}$ photochemical degradation is unknown. If we want to use the $\delta^{13} \mathrm{C}_{\mathrm{MeHg}}$ to understand the origin of the $\mathrm{C}$ source in $\mathrm{MeHg}$, then we need to account for $\mathrm{C}$ isotope fractionation during $\mathrm{MeHg}$ breakdown. In the present work we repeated the photodegradation studies by Bergquist and Blum as well as those of Zhang and Hsu-Kim, to analyze and characterize $\mathrm{C}$ isotope fractionation of the methyl group of $\mathrm{MeHg}$ by using a new compound specific isotope analysis technique (CSIA): purge and trap - gas chromatography - combustion - isotope ratio mass spectrometry (PT-GC-C-IRMS)[3], [4].

[1] B. A. Bergquist and J. D. Blum, "Mass-Dependent and IndependentFractionation of $\mathrm{Hg}$ Isotopes byPhotoreduction in Aquatic Systems," Sci. Rep., vol. 318, pp. 417-420, 2007, [Online].

Available: http://citeseerx.ist.psu.edu/viewdoc/download? doi=10.1.1.894.8580\&rep=rep1\&type $=$ pdf.

[2] T. Zhang and H. Hsu-Kim, "Photolytic degradation of methylmercury enhanced by binding to natural organic ligands," Nat Geosci, vol. 892, pp. 473-476, 2010, doi: doi:10.1038/ngeo892.

[3] J. Masbou, et. al., "Carbon Stable Isotope Analysis of Methylmercury Toxin in Biological Materials by Gas Chromatography Isotope Ratio Mass Spectrometry," Anal. Chem., vol. 87, no. 23, pp. 11732-11738, 2015, doi: 10.1021/acs.analchem.5b02918.

[4] S. Queipo-Abad, et.al., "Sensitive determination of methylmercury $\delta 13 \mathrm{C}$ compound specific stable isotopic analysis by purge and trap gas chromatography combustion isotope ratio mass spectrometry," J. Chromatogr. A, vol. 1617, p. 460821, 2020, doi: 10.1016/j.chroma.2019.460821. 